\title{
Histological observation of doublesex-mab 3-related transcription factor 1 (DMRT1) localization in the adult testis of three-spot wrasse
}

\author{
Yasuhisa Kobayashi • Ryo Nozu • Ryo Horiguchi • \\ Masaru Nakamura
}

Received: 2 April 2014/ Accepted: 10 June 2014/Published online: 19 June 2014

(C) The Author(s) 2014. This article is published with open access at Springerlink.com

\begin{abstract}
Doublesex-mab 3-related transcription factor 1 (DMRT1) has been identified as the first conserved gene involved in the testicular differentiation of vertebrates. However, the precise role of DMRT1 in spermatogenesis has not been made clear. In this study, immunohistochemical method was used to observe DMRT1 protein localization in order to resolve cellular profile of DMRT1 in the adult testis of three-spot wrasse. DMRT1 protein was clearly and specifically localized in the Sertoli cells of all spermatogenic cells and epithelial cells comprising the efferent duct, but not in the germ cells. In addition, adult males were treated with aromatase inhibitor (AI) for investigating the role of estrogen on the transcription of DMRT1. AI treatment caused an increase in the levels of DMRT1 transcripts in the efferent duct region, concomitant with a decrease in spermatogonia and spermatocytes.
\end{abstract}

Keywords DMRT1 Spermatogenesis $\cdot$ Efferent duct $\cdot$ Wrasse $\cdot$ Aromatase inhibitor $\cdot$ Sertoli cell

$\begin{array}{ll}\text { Abbreviations } \\ \text { DMRT1 } & \text { Doublesex-mab 3-related transcription factor 1 } \\ \text { E2 } & \text { Estradiol-17beta } \\ \text { AI } & \text { Aromatase inhibitor } \\ \text { SG } & \text { Spermatogonia }\end{array}$

Y. Kobayashi $(\bowtie)$

Faculty of Science, Ushimado Marine Institute (UMI), Okayama University, Ushimado, Setouchi 701-4303, Japan

e-mail: yasu_koba@cc.okayama-u.ac.jp

Y. Kobayashi · R. Nozu · R. Horiguchi · M. Nakamura

Tropical Biosphere Research Center, Sesoko Station, University of the Ryukyus, 3422 Sesoko, Motobu, Okinawa 905-0227,

Japan

R. Nozu

e-mail: r-nozu@okichura.jp

R. Horiguchi

e-mail: horigu@xb3.so-net.ne.jp

M. Nakamura

e-mail: m-nakamura@okichura.jp

R. Nozu $\cdot$ M. Nakamura

Okinawa Churashima Foundation, 888 Ishikawa, Motobu, Okinawa 905-0206, Japan

R. Horiguchi

Department of Biology, Hamamatsu University School of Medicine, Hamamatsu 431-3192, Japan 


$\begin{array}{ll}\text { PSC } & \text { Primary spermatocytes } \\ \text { SSC } & \text { Secondary spermatocytes } \\ \text { ST } & \text { Spermatids } \\ \text { SZ } & \text { Spermatozoa } \\ \text { ED } & \text { Efferent duct } \\ \text { IP } & \text { Initial phase } \\ \text { TP } & \text { Terminal phase }\end{array}$

\section{Background}

The sex of almost all animals is determined during early life stages. Once determined, the sex of an individual remains the same for the remainder of the life. However, some fishes can change their sexes naturally (Devlin and Nagahama 2002; Frisch 2004; Kobayashi et al. 2013). As sex change in such hermaphroditic fishes involves gonadal reconstruction after reaching adulthood, they serve as good animal models for the investigation of gonadal sex determination/differentiation in vertebrates.

The three-spot wrasse, Halichoeres trimaculatus, which is common to coral reefs in Okinawa, Japan, is one of the protogynous sex-changing fish (Takemura et al. 2008). Individuals of this species mature initially as either males or females. Under appropriate social conditions, initial phase (IP) males and females become terminal phase (TP) males (Hourigan et al. 1991; Kuwamura et al. 2000). Ovaries of the female, which initially have no detectable testicular tissue, are restructured into fully functional testes during sex change (Hourigan et al. 1991). The mechanisms underlying this sex-changing process are largely unknown. Previously, the suppression of aromatase activity via the administration of non-steroidal aromatase inhibitor (AI) in IP females induced a complete female-to-male sex change (Nozu et al. 2009). This result strongly indicated that estrogen is required for the maintenance of ovarian structure in this fish. The genes related to testicular determination/differentiation might be up-regulated in AI-treated sex-changing gonad (Horiguchi et al. 2013; Nozu et al. in preparation).

DMRT1 (doublesex and mab-3 related transcription factor 1) encodes a putative transcriptional factor which is found in a cluster with two other members of the gene family, having in common a zinc finger-like DNA-binding motif (DM domain) (Erdman and Burtis 1993). This gene exhibits a gonad-specific and sexually dimorphic expression pattern during testicular differentiation process in various vertebrate species (Fernandino et al. 2006). DMRT1 knockout mice revealed that it is required for postnatal testicular development in males (Raymond et al. 1999). In chicken, DMRT1 was identified as the key gene for male sex determination (Smith et al. 2009). Furthermore, DMY, duplicated copy of autosomal DMRT1, was identified as the sexdetermination gene of medaka (Matsuda et al. 2002). Therefore, DMRT1 was identified as one of the most important and conserved testicular determination factor in vertebrates. Investigations on the role of DMRT1 in testicular differentiation revealed that its function is limited to a very narrow window during spermatogenesis. In rainbow trout (Marchand et al. 2000) and pejerrey (Fernandino et al. 2006), DMRT1 expression was found to be high throughout spermatogenesis, but low during spermiation. These reports indicate that seasonal change in DMRT1 expression may contribute to the maintenance of testicular cycle. However, information on the cellar distribution of DMRT1 within the testis is not clear.

Furthermore, exposure of female embryos to androgen or AI during early stages of gonadal sex differentiation resulted in the sex-reversal of the adults accompanied by DMRT1 up-regulation in tilapia (Kobayashi et al. 2008), catfish (Raghuveer and Senthilkumaran 2009) and rainbow trout (Le Gac et al. 2008; Schulz et al. 2007). In contrast, suppression of DMRT1 transcripts in the gonads was observed in estrogen (E2)-treated male embryos of zebrafish (Schulz et al. 2007) and tilapia (Kobayashi et al. 2008). In addition, changes were noticed in DMRT1 expression in concordance with the phases of testicular differentiation in several fishes that change their sexes naturally (Alam et al. 2008; He et al. 2003; Liarte et al. 2007). These findings suggest that DMRT1 is involved not only in early testicular differentiation, but also in gonadal sex reversal/change in teleosts. Our interest here was to find out the involvement of DMRT1 in the gonadal sex change of three-spot wrasse. In fact, DMRT1 expressed significantly higher in the testis than in the ovary of three-spot wrasse. We also observed up-regulation of DMRT1 transcripts in the AI-treated sex-changing gonad of three-spot wrasse 
(Horiguchi et al. in preparation). However, the mechanism by which AI elevates DMRT1 expression in the gonads of three-spot wrasse during sex change has not been established till date.

To investigate the role of DMRT1 in spermatogenesis of three-spot wrasse, we examined the localization of DMRT1 protein in the adult testis of IP males using specific antibody in this study. In addition, we investigated the effect of AI on DMRT1 expression in IP male of three-spot wrasse.

\section{Materials and methods}

Animals and sample collection

Adult three-spot wrasses were collected by roll net from Sesoko Beach (Okinawa prefecture, Japan) and then maintained in 500-1 tanks with flow-through seawater at Sesoko Station, Tropical Biosphere Research Center, University of the Ryukyus. The sex of the fish was determined by applying light pressure on the abdomen to elicit gamete release. Fish that did not release sperm were regarded as female. Initial phase males were distinguished from TP males on the basis of body coloration. Initial phase males (average of total lengths $=10.4 \pm 0.65 \mathrm{~cm}$ ) were kept in one aquarium with a dominant male and a small female, the social cues of which inhibit sex change of the other fish in either direction. Before sampling, IP males were anesthetized with $0.05 \%$ 2-phenoxyethanol (Wako chemicals, Osaka, Japan), and total length and body weight were determined. Then, the testes were removed and weighed. The gonadal fragments were fixed in Bouin's solution. The experiments were performed under approval of the University of the Ryukyus animal care committee.

\section{Immunohistochemistry}

To identify the cellular localization of DMRT1 in testis, we used an immunohistochemical approach. Detection and visualization of the primary antibodies were accomplished using a Histofine Immuno Stain Kit (Nichirei Corp., Tokyo, Japan) according to the manufacturer's instructions. Briefly, seven testis samples fixed with Bouin's solution were dehydrated in a series of alcohol, clarified in Lemosol coagulant (Wako), and then embedded in paraffin. Cross-sections were cut at 7- $\mu \mathrm{m}$ thickness. After deparaffinization and dehydration, sections were rinsed in $0.1 \mathrm{M}$ PBS. They were then treated with $0.3 \% \mathrm{H}_{2} \mathrm{O}_{2}$ for $15 \mathrm{~min}$ to block endogenous peroxidase. Following incubation with $10 \%$ normal goat serum for 15 min, the sections were incubated with primary rabbit antibody against wrasse DMRT1 protein. The primary antibody signals were visualized with HRP chromogenic substrate using 3,3'-diaminobenzidine (DAB, Wako). Anti-DMRT1, which recognizes the $\mathrm{N}$ - and C-terminus regions (MSKGKHSKQVPEPTEPLC and CETPDFTVNTIMDGDATK, respectively) of wrasse DMRT1, was used at a 6,000-fold dilution (Horiguchi et al. in preparation). Sections were lightly counterstained with hematoxylin. As a control, BSA and normal rabbit serum were applied instead of the primary antibody. No significant immunoreactive signals were detected in the controls (data not shown). The size of DMRT1 positive cells at different stages of spermatogenesis was determined with ImageJ software (ver. 1.42q, NIH, USA). At least 40 DMRT1-positive cells at different stages were analyzed.

Aromatase inhibitor treatment

We used in this study exemestane (EM), a steroidal chemical component (trade name, Aromasin) (Pfizer Japan Inc., Tokyo, Japan) as the AI. According to previous study (Kobayashi et al. 2011), exemestane and E2 (Sigma, St. Louis, MO) were dissolved in $100 \%$ ethanol and added to commercial fish feed and then dried overnight. Fish were fed twice daily for 10 weeks on a diet containing different doses of EM alone (AI_low, $2 \mu \mathrm{g}$ EM/g diet; AI_high, $200 \mu \mathrm{g}$ EM/g diet) or in combination with E2 (AI + E2, $2 \mu \mathrm{g}$ EM and $2 \mu \mathrm{g}$ E2/g diet). All fish in the control group were fed a normal diet, i.e., one without these additions. Treatment with AI significantly decreased with E2 production (Kobayashi et al. 2011).

Samples were collected after 10 weeks of treatment. Before sampling, all fish were anesthetized with $0.05 \%$ 2-phenoxyethanol (Wako), and total length, body weight, and body colors were determined. Then, the testes were removed and weighed. Pieces of the testis were pooled in a microcentrifuge tube with RNAlater 
A
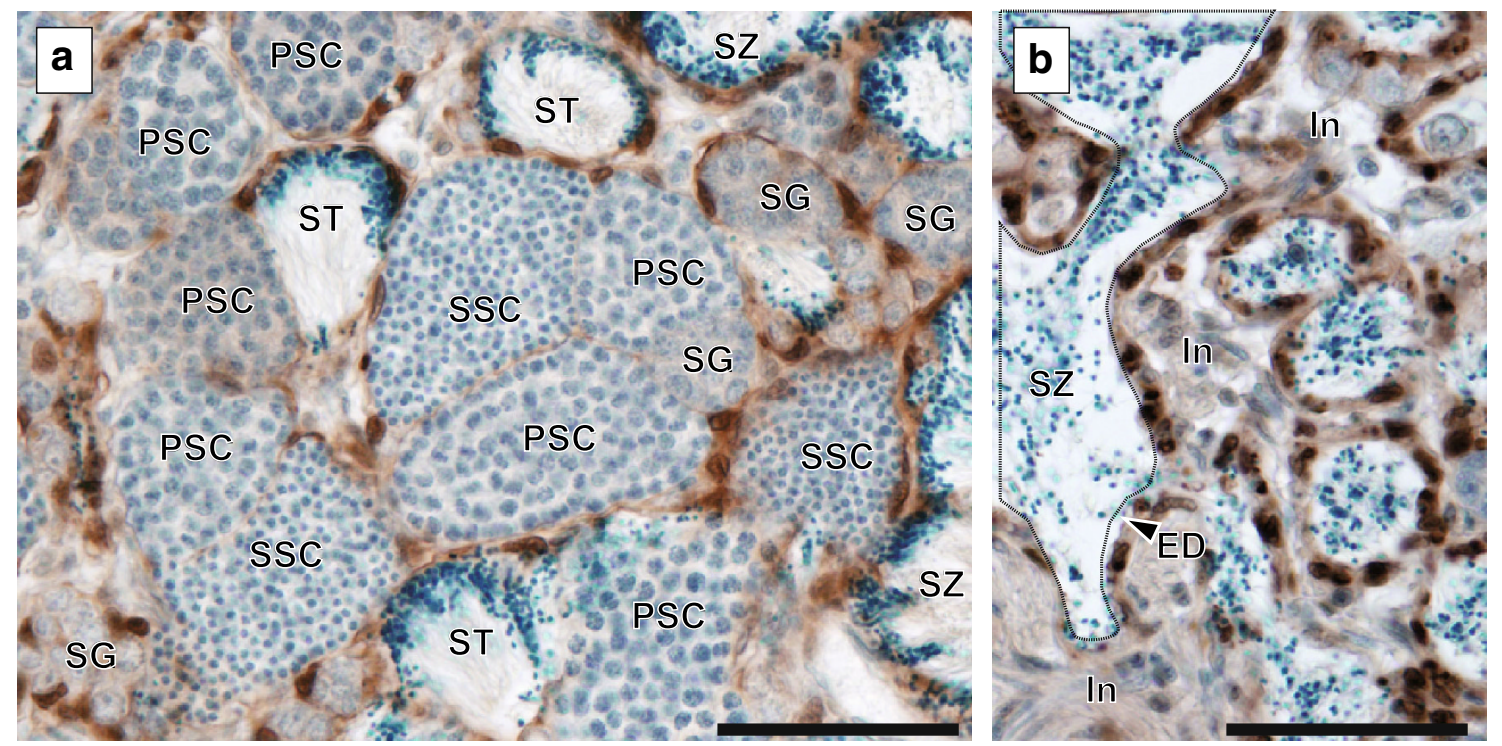

B Spermatgonia

(SG)

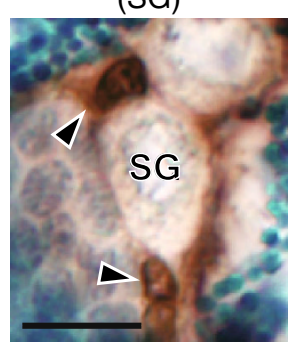

Spermatid (ST)

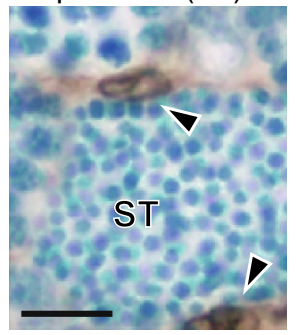

Primary spermatocyte (PSC)

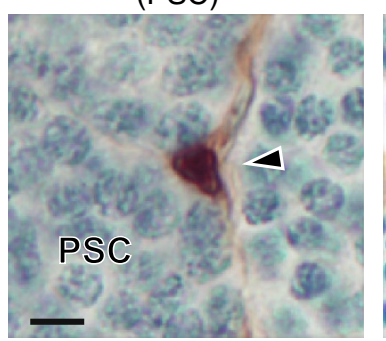

Spermatozoa (SZ)

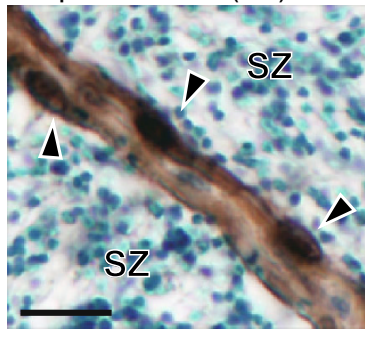

(SSC)
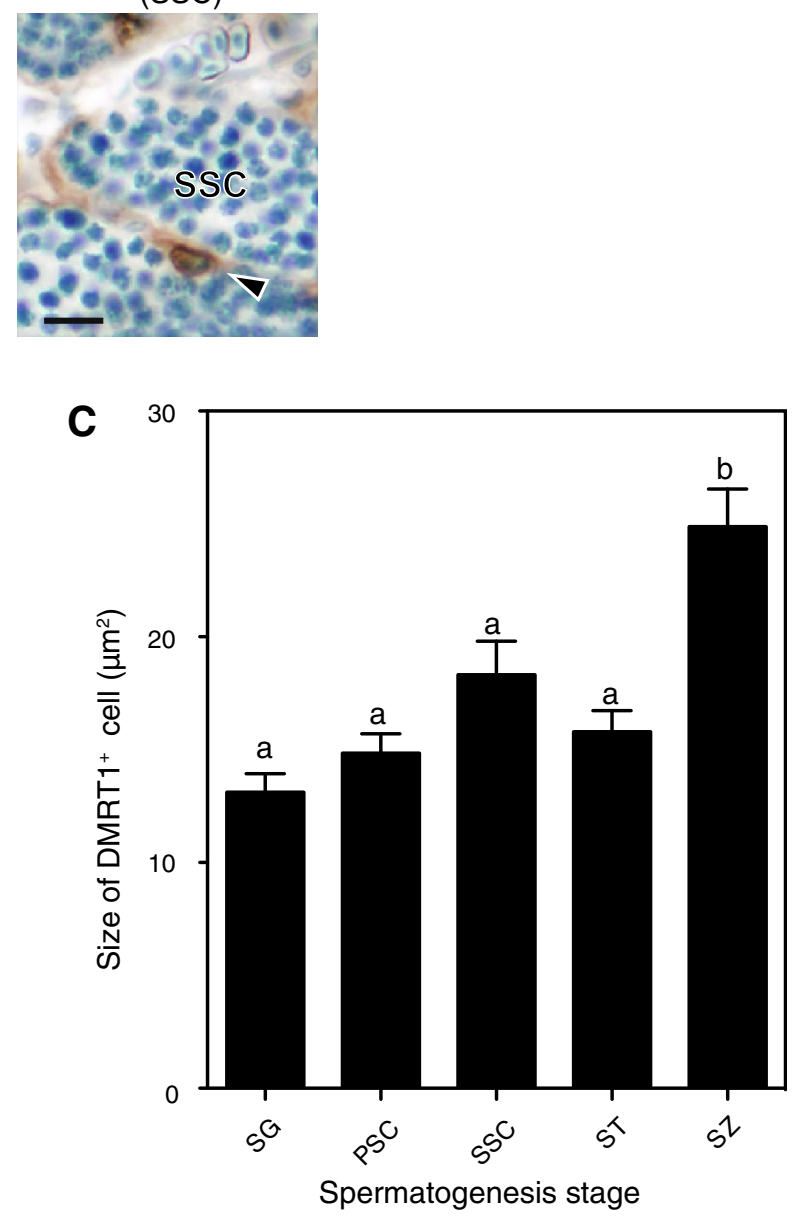
Fig. 1 Localizations of DMRT1 protein in the adult IP male testis. A Representative sections of testis ( $a$, middle part of testis. $b$, close to the efferent ducts) immunostained with antibody for wrasse DMRT1 (brown), counter stained with hematoxylin. Broken line indicates efferent duct. Bars indicate $50 \mu \mathrm{m}$. B DMRT1-positive cells (arrowhead) at different stages of spermatogenesis. Bars indicate $10 \mu \mathrm{m}$. C Sizes of DMRT1 immuno-positive cells (DMRT1 ${ }^{+}$) at different stages of spermatogenesis. Values are mean \pm SEM and sharing the same letter indicates no significant difference $(P<0.05)$. $S G$ spermatogonia, $P S C$ primary spermatocyte, $S S C$ secondary spermatocyte, $S T$ spermatid, $S Z$ spermatozoa, $E D$ efferent duct, $I n$ interstitium

reagent (Ambion, TX) and stored at $-30{ }^{\circ} \mathrm{C}$ until RNA extraction. The remaining gonadal fragment was fixed in Bouin's solution for immunohistochemical observations of DMRT1 protein as described above. To determine the ratio of efferent duct in testis, we measured the area of efferent duct in 10 randomly selected areas $\left(200 \mu \mathrm{m}^{2}\right)$ in the testis of each fish using ImageJ software.

\section{Real-time RT-PCR for DMRT1}

Transcripts of wrasse DMRT1 in the testis were quantified using a real-time RT-PCR assay. Briefly, total RNA was isolated from individual testis stored in RNAlater using the RNeasy mini kit (Qiagen, Netherlands) according to the manufacturer's instructions. Samples were reverse-transcribed from $500 \mathrm{ng}$ of total RNA in a $20-\mu l$ volume using random hexamer primers and OmniScript reverse transcriptase (Qiagen). Two microliters of these diluted cDNA samples were used in $22 \mu \mathrm{l}$ PCR reactions with SYBER Premix Ex Taq (Takara Bio Inc., Shiga, Japan) with the ABI 7000 sequence detection system. Assays (in triplicate) were repeated at least twice with the constitutive elongation factor $1 \alpha$ (ef1a) as a normalizing control. Primer pairs were designed using Primer3 software (Rozen and Skaletsky 2000). The relative changes in mRNA expression were determined using $2^{-\Delta \Delta} \mathrm{Ct}$ method (Livak and Schmittgen 2001). The following primers were applied for realtime RT-PCR assay: DMRT1 forward, 5'-aagagatgagcaagggcaag-3'; DMRT1 reverse, 5'-agacacaaaaccgtggttcc-3'; ef1a forward, 5'-aagggagccgatcacttcaa-3'; ef1a reverse, 5'-aatccagcacaggtgcgtaa-3'. Real-time RT-PCR efficiency ranged between 96 and $100 \%$. Amplicons were sequenced to confirm RT-PCR specificity.

Statistical analysis

One-way ANOVA was used to compare mean values of the result of real-time RT-PCR and ratio of efferent duct, followed by Tukey-Kramer Multiple comparison test using PRISM 5.0b software (GraphPad, San Diego, CA). The results are presented as mean \pm SEM.

Fig. 2 Effect of AI treatments on DMRT1 transcripts in the testis of the three-spot wrasse. Three-spot wrasses (IP males) were treated for 10 weeks with a normal diet (control; $n=7), 2 \mu \mathrm{g}$ exemestane (EM)/g diet (AI_low; $n=7), 200 \mu \mathrm{g}$ EM/g diet (AI_high; $n=7$ ), $2 \mu \mathrm{g}$ EM and $2 \mu \mathrm{g}$ E2/g diet $(\mathrm{AI}+\mathrm{E} 2 ; n=7)$. Values are mean $\pm \mathrm{SEM}$ and sharing the same letter indicates no significant difference $(P<0.05)$

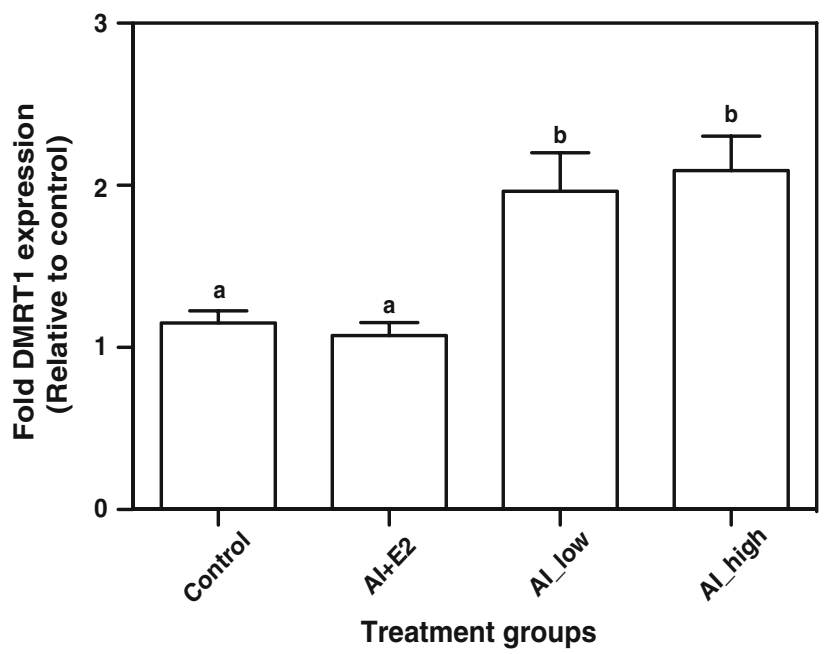

Springer 

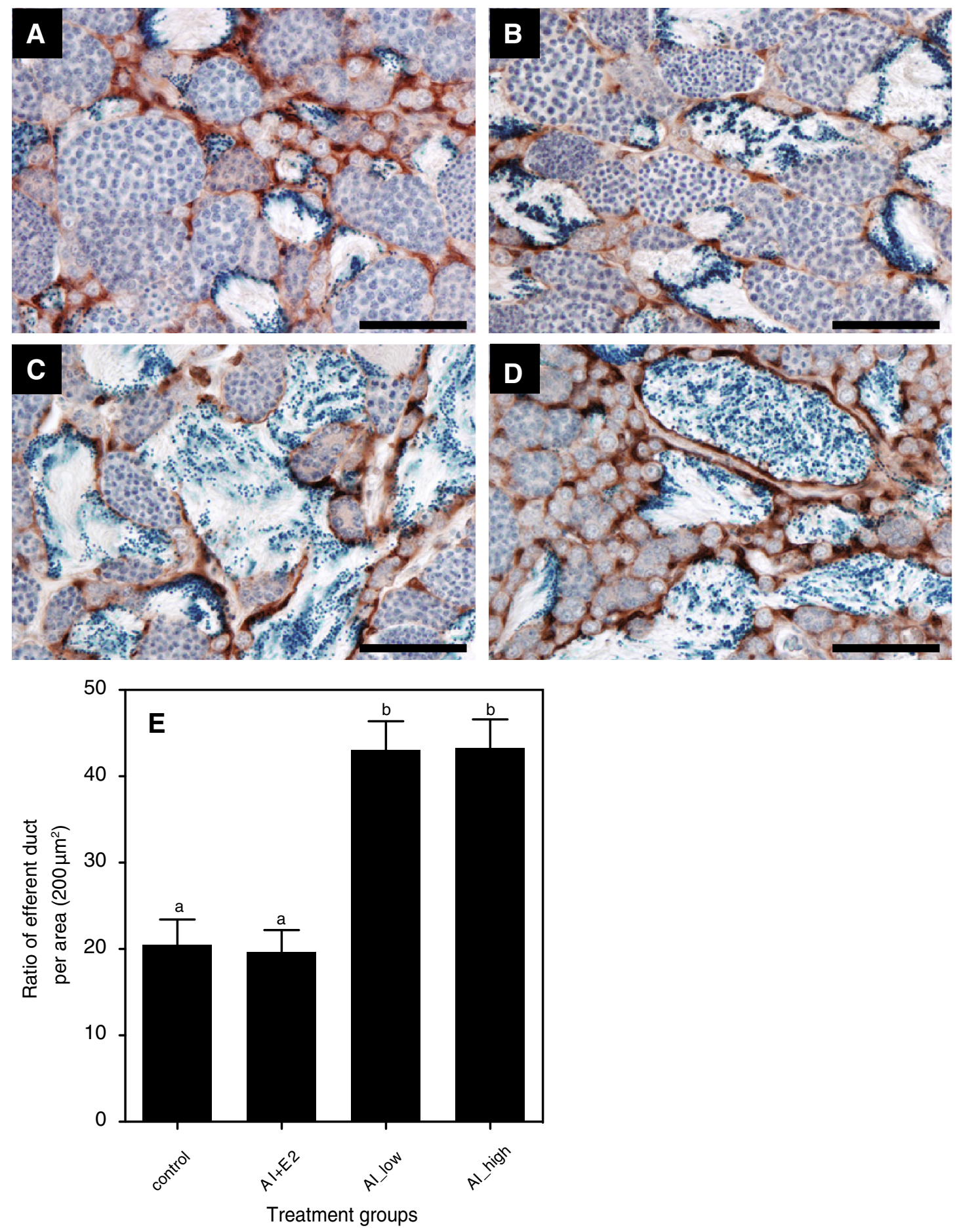

Fig. 3 Sections of testis treated with AI, immunostained with antibody for wrasse DMRT1. a Control, b AI + E2, c AI_low and d AI_high groups. Brown stained cells indicate positive signal. Bars indicate $50 \mu \mathrm{m}$. e Effect of AI treatment on the ratio of efferent ducts filled with spermatozoa in different treatment groups. Ratio was calibrated against the randomly selected area $\left(200 \mu \mathrm{m}^{2}\right)$. Values are mean \pm SEM and sharing the same letter indicates no significant difference $(P<0.05)$ 


\section{Results}

Localization of DMRT1 protein in IP male testis

The protein localization of DMRT1 in IP male testis was observed by immunohistochemistry (Fig. 1). DMRT1 proteins were specifically expressed in Sertoli cells (Fig. 1Aa) and epithelial cells comprising the efferent duct (Fig. 1Ab), but not in germ cells and interstitium. Positive signals were observed in the cysts at all cellular stages of spermatogenesis (Fig. 1B). Figure 1C shows the differences in the size of DMRT1 expressing cells at various stages of spermatogenesis. Size of the epithelial cells lining the efferent duct filled with spermatozoa was significantly larger than Sertoli cells surrounding the spermatogenic cysts (Fig. 1C).

Effect of AI on DMRT1 transcripts and localization in the testis

To clarify the effect of AI on DMRT1 expression in the testis, we measured DMRT1 transcript in AI-treated testis by using real-time RT-PCR (Fig. 2). AI treatment increased DMRT1 expression significantly, and these increases were blocked by co-treatment with E2 (Fig. 2).

Immunohistological observation of DMRT1 during different phases of testicular changes is shown in Fig. 3. Similar to control, positive signals were observed specifically in the Sertoli and epithelial cells of AI-treated testis (Fig. 3a-d). Previously, we confirmed that AI treatment induce the proliferation of spermatogonia (Kobayashi et al. 2011), thus relative ratio of efferent duct in the AI-treated testis was higher than the control and co-treatment groups (Fig. 3e).

\section{Discussion}

In this study, we observed detailed localization of DMRT1 protein in the IP male testis of three-spot wrasse. In addition, we investigated the effect of AI on the DMRT1 expression in the testis of IP male.

DMRT1 has been cloned in several vertebrates and its involvement in testicular differentiation was investigated extensively (Ferguson-Smith 2007; Ijiri et al. 2008; Raymond et al. 2000). However, the precise role of DMRT1 during spermatogenesis remains largely unknown. Based on immunohistological observation in this study, we have been able to characterize that DMRT1 is localized specifically and ubiquitously to the Sertoli cells surrounding all spermatogenic stages and epithelial cells that constitute the efferent duct in the testis of three-spot wrasse. It is noteworthy that we did not find any DMRT1-positive signals in germ cells and interstitium including Leydig cells. These observations were in good agreement with tilapia (Kobayashi et al. 2008) and medaka (Kobayashi et al. 2004; Nakamoto et al. 2009). It is well known Sertoli cells play a critical role in spermatogenesis by controlling the survival and development of germ cells through cell-cell contact in the testis of all vertebrates (Schulz et al. 2005; Sharpe et al. 2003). Therefore, DMRT1 may contribute to spermatogenesis by expression in the Sertoli cell and also maintenance/formation of the efferent duct in threespot wrasse. In contrast to our data, DMRT1 was found to be expressed not only in the Sertoli cells, but also in the spermatogonia in catfish (Raghuveer and Senthilkumaran 2009) and zebrafish (Guo et al. 2005). In addition, DMRT1 was not expressed in the Sertoli cells in the protogynous grouper (Xia et al. 2007). Such discrepancies warrant further studies to confirm the conserved role of DMRT1 in spermatogenesis of teleosts. Previously, we confirmed that estrogen has an important role in the spermatogenesis of three-spot wrasse (Kobayashi et al. 2011) similar to other teleosts (Schulz et al. 2010). Indeed, AI treatment to IP male inhibited the renewal and proliferation of spermatogonia, corollary of the ratio of spermatocyte and spermatozoa were increased (Kobayashi et al. 2011). We showed here that 10 weeks of AI treatment induced the up-regulation of DMRT1 transcripts in IP male testis. Previous studies have shown that the expression of DMRT1 was upregulated by AI treatment prior to sexual differentiation in tilapia (Kobayashi et al. 2008) and chicken (Smith et al. 2003). However, the effect of AI on DMRT1 transcription is not yet clear. We believe that AI effect is indirect on DMRT1 expression for the following reasons. First, immunohistochemical signal strength and localization of DMRT1 in testis were similar between control and AI-treatment groups (Figs. 1A, 3a-d). Second, the $5^{\prime}$-flanking region of the DMRT1 gene of other wrasse species, Halichoeres tenuispinis, has been isolated, and it did not have estrogen- or androgen-response element (Jeong et al. 2009). Taken together, we 
speculate that in the three-spot wrasse, DMRT1 was up-regulated in the presence of AI, presumably due to changes in the proportion of germ cell types in the testis. Our data are consistent with a report showing that DMRT1 transcript was not suppressed during the early process of estrogen-induced feminization in rainbow trout (Vizziano-Cantonnet et al. 2008). Therefore, DMRT1 transcription might not be regulated by steroid hormones. Further investigation will be necessary to clarify the mechanisms underlying DMRT1 transcriptional regulation.

\section{Conclusion}

In this study, we identified the localization of DMRT1 in adult testis. DMRT1 protein was specifically localized in the Sertoli-cell linage but not in spermatogonia. DMRT1 might be a good marker for investigating the mechanism of Sertoli cell differentiation and efferent duct formation during sex change in three-spot wrasse. In addition, AI treatment studies revealed a part of the transcriptional mechanism of DMRT1.

Acknowledgments This work was supported by JSPS Research Fellowship for Young Scientists.

Conflict of interest The authors declare that they have no competing interests.

Authors' contributions YK conceived of the study, participated in its design and coordination, and drafted the manuscript. RN, $\mathrm{RH}$ and MN helped perform the experiments and draft the manuscript. All authors read and approved the final manuscript.

Open Access This article is distributed under the terms of the Creative Commons Attribution License which permits any use, distribution, and reproduction in any medium, provided the original author(s) and the source are credited.

\section{References}

Alam MA, Kobayashi Y, Horiguchi R, Hirai T, Nakamura M (2008) Molecular cloning and quantitative expression of sexually dimorphic markers dmrt1 and fox12 during female-to-male sex change in Epinephelus merra. Gen Comp Endocrinol 157(1):75-85

Devlin RH, Nagahama Y (2002) Sex determination and sex differentiation in fish: an overview of genetic, physiological, and environmental influences. Aquaculture 208(3-4):191-364

Erdman SE, Burtis KC (1993) The drosophila doublesex proteins share a novel zinc finger related DNA binding domain. EMBO J 12(2):527-535

Ferguson-Smith M (2007) The evolution of sex chromosomes and sex determination in vertebrates and the key role of dmrt1. Sex Dev 1(1):2-11

Fernandino JI, Guilgur LG, Somoza GM (2006) Dmrt1 expression analysis during spermatogenesis in pejerrey, Odontesthes bonariensis. Fish Physiol Biochem 32(3):231-240

Frisch A (2004) Sex-change and gonadal steroids in sequentially-hermaphroditic teleost fish. Rev Fish Biol Fisher 14(4):481-499

Guo Y, Cheng H, Huang X, Gao S, Yu H, Zhou R (2005) Gene structure, multiple alternative splicing, and expression in gonads of zebrafish dmrt1. Biochem Biophys Res Commun 330(3):950-957

He CL, Du JL, Wu GC, Lee YH, Sun LT, Chang CF (2003) Differential dmrt1 transcripts in gonads of the protandrous black porgy, Acanthopagrus schlegeli. Cytogenet Genome Res 101(3-4):309-313

Horiguchi R, Nozu R, Hirai T, Kobayashi Y, Nagahama Y, Nakamura M (2013) Characterization of gonadal soma-derived factor expression during sex change in the protogynous wrasse, Halichoeres trimaculatus. Dev Dyn 242(4):388-399

Hourigan TF, Nakamura M, Nagahama Y, Yamauchi K, Grau EG (1991) Histology, ultrastructure, and in vitro steroidogenesis of the testes of two male phenotypes of the protogynous fish, Thalassoma duperrey (labridae). Gen Comp Endocrinol 83(2):193-217

Ijiri S, Kaneko H, Kobayashi T, Wang DS, Sakai F, Paul-Prasanth B, Nakamura M, Nagahama Y (2008) Sexual dimorphic expression of genes in gonads during early differentiation of a teleost fish, the nile tilapia Oreochromis niloticus. Biol Reprod 78(2):333-341

Jeong HB, Park JG, Park YJ, Takemura A, Hur SP, Lee YD, Kim SJ (2009) Isolation and characterization of dmrt1 and its putative regulatory region in the protogynous wrasse, Halichoeres tenuispinis. Gene 438(1-2):8-16

Kobayashi T, Matsuda M, Kajiura-Kobayashi H, Suzuki A, Saito N, Nakamoto M, Shibata N, Nagahama Y (2004) Two dm domain genes, dmy and dmrt1, involved in testicular differentiation and development in the medaka, Oryzias latipes. Dev Dyn 231(3):518-526

Kobayashi T, Kajiura-Kobayashi H, Guan G, Nagahama Y (2008) Sexual dimorphic expression of dmrt1 and sox9a during gonadal differentiation and hormone-induced sex reversal in the teleost fish nile tilapia (Oreochromis niloticus). Dev Dyn 237(1):297-306 
Kobayashi Y, Nozu R, Nakamura M (2011) Role of estrogen in spermatogenesis in initial phase males of the three-spot wrasse (Halichoeres trimaculatus): effect of aromatase inhibitor on the testis. Dev Dyn 240(1):116-121

Kobayashi Y, Nagahama Y, Nakamura M (2013) Diversity and plasticity of sex determination and differentiation in fishes. Sex Dev 7(1-3):115-125

Kuwamura T, Karino K, Nakashima Y (2000) Male morphological characteristics and mating success in a protogynous coral reef fish, Halichoeres melanurus. J Ethol 18(1):17-23

Le Gac F, Lareyre JJ, Montfort J, Esquerre D, Houlgatte R (2008) Transcriptional analysis of spermatogenesis regulation by sex steroids in trout. Cybium 32(2):119-121

Liarte S, Chaves-Pozo E, Garcia-Alcazar A, Mulero V, Meseguer J, Garcia-Ayala A (2007) Testicular involution prior to sex change in gilthead seabream is characterized by a decrease in dmrt1 gene expression and by massive leukocyte infiltration. Reprod Biol Endocrinol 5:20

Livak KJ, Schmittgen TD (2001) Analysis of relative gene expression data using real-time quantitative pcr and the 2(-delta delta $\mathrm{c}(\mathrm{t}))$ method. Methods 25(4):402-408

Marchand O, Govoroun M, D'Cotta H, McMeel O, Lareyre J, Bernot A, Laudet V, Guiguen Y (2000) Dmrt1 expression during gonadal differentiation and spermatogenesis in the rainbow trout, Oncorhynchus mykiss. Biochim Biophys Acta 1493(1-2):180-187

Matsuda M, Nagahama Y, Shinomiya A, Sato T, Matsuda C, Kobayashi T, Morrey CE, Shibata N, Asakawa S, Shimizu N, Hori H, Hamaguchi S, Sakaizumi M (2002) Dmy is a y-specific dm-domain gene required for male development in the medaka fish. Nature 417(6888):559-563

Nakamoto M, Muramatsu S, Yoshida S, Matsuda M, Nagahama Y, Shibatal N (2009) Gonadal sex differentiation and expression of sox9a2, dmrt1, and fox12 in Oryzias luzonensis. Genesis 47(5):289-299

Nozu R, Kojima Y, Nakamura M (2009) Short term treatment with aromatase inhibitor induces sex change in the protogynous wrasse, Halichoeres trimaculatus. Gen Comp Endocrinol 161(3):360-364

Raghuveer K, Senthilkumaran B (2009) Identification of multiple dmrt1s in catfish: localization, dimorphic expression pattern, changes during testicular cycle and after methyltestosterone treatment. J Mol Endocrinol 42(5):437-448

Raymond CS, Kettlewell JR, Hirsch B, Bardwell VJ, Zarkower D (1999) Expression of dmrt1 in the genital ridge of mouse and chicken embryos suggests a role in vertebrate sexual development. Dev Biol 215(2):208-220

Raymond CS, Murphy MW, O'Sullivan MG, Bardwell VJ, Zarkower D (2000) Dmrt1, a gene related to worm and fly sexual regulators, is required for mammalian testis differentiation. Gene Dev 14(20):2587-2595

Rozen S, Skaletsky H (2000) Primer3 on the www for general users and for biologist programmers. Methods Mol Biol 132:365-386

Schulz RW, Menting S, Bogerd J, Franca LR, Vilela DA, Godinho HP (2005) Sertoli cell proliferation in the adult testis-evidence from two fish species belonging to different orders. Biol Reprod 73(5):891-898

Schulz RW, Bogerd J, Male R, Ball J, Fenske M, Olsen LC, Tyler CR (2007) Estrogen-induced alterations in amh and dmrt1 expression signal for disruption in male sexual development in the zebrafish. Environ Sci Technol 41(17):6305-6310

Schulz RW, de Franca LR, Lareyre JJ, LeGac F, Chiarini-Garcia H, Nobrega RH, Miura T (2010) Spermatogenesis in fish. Gen Comp Endocrinol 165(3):390-411

Sharpe RM, McKinnell C, Kivlin C, Fisher JS (2003) Proliferation and functional maturation of sertoli cells, and their relevance to disorders of testis function in adulthood. Reproduction 125(6):769-784

Smith CA, Katz M, Sinclair AH (2003) Dmrt1 is upregulated in the gonads during female-to-male sex reversal in zw chicken embryos. Biol Reprod 68(2):560-570

Smith CA, Roeszler KN, Ohnesorg T, Cummins DM, Farlie PG, Doran TJ, Sinclair AH (2009) The avian z-linked gene dmrt1 is required for male sex determination in the chicken. Nature 461(7261):267-271

Takemura A, Oya R, Shibata Y, Enomoto Y, Uchimura M, Nakamura S (2008) Role of the tidal cycle in the gonadal development and spawning of the tropical wrasse Halichoeres trimaculatus. Zool Sci 25(6):572-579

Vizziano-Cantonnet D, Baron D, Mahe S, Cauty C, Fostier A, Guiguen Y (2008) Estrogen treatment up-regulates female genes but does not suppress all early testicular markers during rainbow trout male-to-female gonadal transdifferentiation. J Mol Endocrinol 41(5-6):277-288

Xia W, Zhou L, Yao B, Li CJ, Gui JF (2007) Differential and spermatogenic cell-specific expression of dmrt1 during sex reversal in protogynous hermaphroditic groupers. Mol Cell Endocrinol 263(1-2):156-172 